\title{
Design, Development and Implementation of Mobile Applications to Support the Educational Process in the Greek Secondary Education System
}

\author{
Eleni Seralidou, Nikos Vallianatos, Dimitra Tsolakou, and Christos Douligeris
}

\begin{abstract}
The purpose of this paper is the design, development and presentation of two applications that are created in order to be used for supporting the students' learning in the Greek secondary education environment. More specifically, we present the structure and the functions of two applications under the names "Aepp_App" and "CS_App". The applications are intended to be used by teachers and students during a lesson as well as outside the classroom settings, with the use of android mobile devices. We present the tools that have been used to develop the mobile applications and the applications' use in the educational process. Additionally, we present the feedback received by teachers, to whom the applications were presented, who seem to like the idea of using game applications for mobile devices in order to enhance their students' interest.
\end{abstract}

Index Terms-Secondary Education, Mobile Devices, Educational Applications.

\section{INTRODUCTION}

Nowadays, mobile devices are very popular in primary and secondary schools. They offer a new way of learning in K-12 education by providing a variety of enhanced features, like the integration of multimedia, and help in solving problems encountered in schools such as overbooked and unavailable computer labs [1] [2]. On the other hand, the students today have different preferences when it comes to learning than they had only a few years ago. For example, they learn at a higher speed, are used to processing visual and dynamic information and prefer learning through gamebased activities [3] [4] [5]. The students are interested in ways that are more engaging and give them more autonomy over their educational experiences and thrive on applications that meet the interest of their generation through captivating technologies [6]. Moreover, mobile media devices can provide opportunities for inclusion, active participation, and social interactions [7] and, subsequently, the mobile phone as a device is becoming a valuable resource in the students' infrastructure for learning [8]. Moreover, today's young people have a positive attitude towards using mobile apps in their daily lives, including in their learning activities [9].

Published on December 19, 2020.

E. Seralidou, Department of Informatics University of Piraeus, Greece. (e-mail: eseralid@unipi.gr)

N.Vallianatos, Department of Informatics University of Piraeus, Greece. (e-mail: nikoss123@windowslive.com)

D. Tsolakou, Department of Informatics University of Piraeus, Greece. (e-mail: dimitratsolakou@yahoo.com)

C. Douligeris, Department of Informatics University of Piraeus, Greece. (e-mail: cdoulig@unipi.gr).
Additionally, we need to mention that the importance of algorithmic problem solving and the necessity of a course on algorithms in secondary education are universally accepted. Nevertheless, the teaching of programming principles - in which an algorithmic way of thinking is fundamental - and of computer science, in general, to secondary education students can be a challenge. Many of the concepts that need to be taught are rather difficult to absorb and comprehend. The situation can be even more stressful for students when exams at a local or at a national level must be taken.

Since 2000 in Greece, the course "Developing Applications in a Programming Environment" (D.A.P.E.) has been taught in the third grade of the Lyceum (Greek Senior High School). The main purpose of the course is to enhance the students' thinking and focus on problem solving techniques. During the school year 2019-2020 the course has been renamed to "Informatics" and its curriculum has been expanded in order to include more programming principles. For all these years, this course is included in the Pan-Hellenic exams for entering tertiary education. Also, for the last six years the course "Introduction to the Principles of Computer Science" (I.P.C.S.) has been taught in the second grade of General and Vocational Lyceums. The main purpose of this course is to introduce students to computer science theory topics, like algorithms and program creation, and also to core areas of applied computer science in order for the students to develop analytical thinking and to be able to name and understand the breadth of various scientific areas of informatics.

Many researchers have developed applications for mobile devices that can be used by the students either independently or as part of the teaching process Besides the students' interest, research has shown that teachers are willing to use mobile technologies and apps as supportive learning tools [10] [11]. Palazzi [12] created a mobile application for computer science learning which included games in the form of quizzes for the operating systems course at the University of Padua. This application helps students acquire knowledge by answering questions provided by the teacher. Through the use of this application, the students may be able to acquire new knowledge stimulated by competition while having fun. Oliveira [13] created two mobile applications named eLogicum and Automatum to support teaching and learning of industrial automation and control courses topics in the UTAD University in Portugal. The students who used the applications provided positive feedback about their use and gave many ideas and suggestions for their expansion. Leinonen et. al. [14] designed two mobile apps for K-12 education students, namely ReFlex and TeamUp, for use in 
student-centered and collaborative learning, in which continuous reflection is an important part of the learning process. The applications were widely evaluated by teachers and the results indicated general positive views of using the apps. Moreover, many researchers also work on educational applications for future use in their works in progress, like for example in Politi and Metafas [11] where the design of the application Class Project Assistant, which aims to support the teachers in the context of project based learning, is presented and in Kirci and Oguzhan Kahraman [15] where an educational mobile application for primary school students, based on the concept of gamification, is proposed.

Furthermore, there exist some applications that specifically support the Greek school lesson "Informatics" that we mentioned above. Even though these mobile applications support the course "Informatics" [16] [17], they have not yet been updated to include the new course's curriculum and no mobile applications exist so far for the course "I.P.C.S.". Thus, there is an urgent need to design and develop applications for mobile devices that can be used by educators and students in order to support the above mentioned courses. These applications should be designed to be used inside and outside the classroom settings, leveraging the students' interest and providing an alternative way of learning based on gaming techniques.

In this paper, we present the structure and the functions of CS_App and Aepp_App, two applications for mobile devices which we developed for secondary education. Furthermore, we discuss the way that these applications can be used in order to support the educational process and we present information about the performed presentation of the mobile applications to teachers and the received feedback.

The rest of this paper is organized as follows. In Section 2 , the advantages and limitations of the use of mobile devices in education are presented. In Section 3, the theoretical foundations are presented followed in Section 4 by the methodology and the innovations of this study. In Section 5, the description of the developed mobile applications is presented, in Section 6 the presentation to teachers is included and Section 7 includes the conclusions and the future steps.

\section{Advantages And Limitations of Using Mobile DEVICES IN EDUCATION}

Learning with mobile devices is growing in popularity given the advantages that come with their use. First of all, their ubiquitous availability along with their low cost, easiness of transport, user-friendliness of their interface and their ability to deliver content in multimodal ways are reasons that have led to the use of mobiles devices for learning [11]. Thus, this technology has a huge potential for use in education [18]. However, there are some disadvantages that need to be taken into account. First of all, some technical issues exist which involve the screen's size or the device's interface. Smartphones, in particular, do not have large screens so reading can be sometimes really hard. Moreover, the various devices do not have the same userfriendly and easy-to-use interface. Additionally, while the students lean towards the entertaining and fun use of mobile devices, the educators are often fearful of them and consider them a distraction. Consequently, the educators must take a step ahead to see how these devices can be used in a positive and productive way in classrooms [19].

Moreover, we need to mention that for designing an educational application it is very important to include features that integrate learning theories with practice in order to achieve a mobile learning environment that includes features connected with the theoretical foundations of learning [20]. The design of many existing applications lacks or does not have a solid connection with any underlying learning theories. Additionally, we need to point out that it is not easy for students to learn and understand programming principles, especially concepts that involve variables or more complex programming structures. This difficulty may derive from various reasons like for example the students' lack of practice or the lack of the required knowledge [21]. This fact also enhances the necessity of creating new educational environments in order to support the teaching and learning process.

In the designing phase of the presented applications in this study, we took under consideration the above mentioned advantages and disadvantages. The idea is that if an application for mobile devices has a clear educational design and content then it can be used supportively during the classroom teaching and for learning outside the school settings. Moreover, if this application has some gaming features it will add the element of fun for students during the learning process. Thus, comparatively with the already existing applications' examples, both applications that are presented in this paper have the following advantages:

- they include theory combined with practice,

- they have a quite satisfactory number of questions, as it will be analyzed in the next paragraphs,

- they are free of charge,

- the user is not by any way restricted and has access to the applications' entire content,

- they are linked with specific educational frameworks, and

- in the Aepp_App the teacher has to ability to add more questions of his choice.

\section{THEORETICAL FOUNDATIONS}

The use of mobile devices for educational purposes is a reality nowadays and in order to achieve their best possible use for learning, a connection with relevant learning theories must be done. The issue of mobile devices use in education and the connection with learning theories is discussed in the following subsections.

\section{A. Mobile Devices in Education}

Most recently, mobile devices have become increasingly important and set a new trend in education, the so-called mobile learning (m-learning) [22]. Mobile learning refers to the implementation of mobile devices in any branch of study [23]. Mobile learning differs from traditional education not only because of the integration of mobile technologies but because it can work in both formal and informal environments, as well as promote both individualized and collaborative network learning. The use of mobile technologies also promotes an informal learning process outside the classroom environment, allowing learning without teacher support [24]. With the rise of apps, access to 
learning content and information is always and everywhere available for students. This ubiquitous availability leads to a variety of learning scenarios and to seamless, contextualized or personal learning [25]. Thus, mobile learning could be one of the promising educational technologies with a significantly positive effect on the usefulness, the ease of use and many other factors that affect the development of students in educational environments [26].

\section{B. M-Learning Framework}

For the development of educational applications, the challenge is to design interactive learning experiences that will motivate students to use them, participate more actively in the learning process and by this way learn [27]. For this purpose, several learning theories have been used as a basis for the development of educational software, such as behaviorism, constructivism and socio-cultural theories, and also many frameworks that integrate mobile devices with learning have been introduced. The use of an educational framework as a basis for the development of an educational application is an essential step in order to make a final product that will support learning in the best possible way.

Given the above, after studying several educational frameworks, in our work we decided to use Diana Laurillard's [28] "Conversational Model" for the design and functionality of our applications. In this twelve - step model (Fig. 1), the framework for creating an educational application is provided by offering continuous interactions between the students and the educational application so that the students will fully understand the lesson's content. To achieve this, constant feedback is provided by the application until the students completely understand the concept that it is taught.

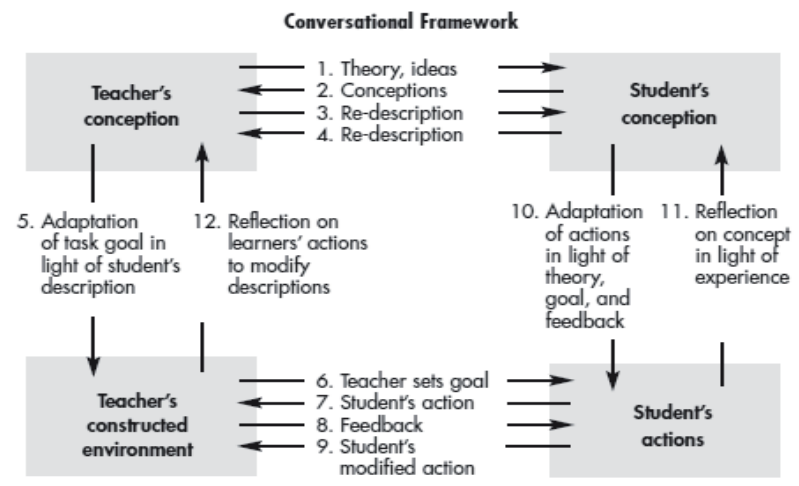

Fig. 1. Diana Laurillard's "Conversational Model"

In the applications presented in this work, several of the framework's features are used for the students to:

- learn the course's theory through playing a questions game,

- give answers according to what they have learned,

- $\quad$ select specific actions in order to better understand the lesson's content,

- receive feedback for their actions and, by this way, improve their knowledge, and

- $\quad$ set learning goals in order to be more motivated.

Furthermore, according to the classification of educational apps presented by Cherner, Dix \& Lee [29], an application's content, purpose and value is very important in order to promote learning. Given their categorization and relation of each category to Bloom's taxonomy, our applications can be characterized firstly as skill-based-apps, where the students are required to recall and remember previously learned knowledge in order to answer questions, and, thus, to develop literacy, testing skills, and subject area knowledge and, secondly, as content-based-apps, where students must conduct research or explore a topic in order to cultivate high order thinking skills because they must evaluate the information provided. These categories apply to the first four levels on the revised Bloom's taxonomy [30] which refer to Remembering, Understanding, Applying and Analyzing (Fig. 2).

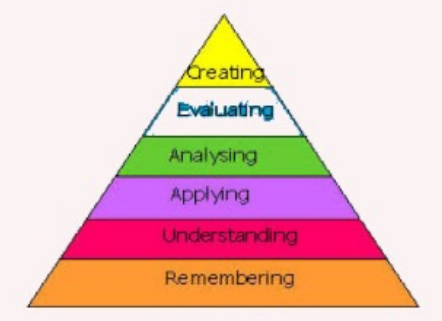

Fig. 2. Revised Bloom's Taxonomy

\section{Methodology ANd InNOVATIONS}

Both of the presented educational applications are addressed to secondary education teachers and students. In their initial design, they fully support the curricula of the courses "Informatics" and "I.P.C.S." by using theoretical and practical examples in the form of quizzes that include multiple choice questions. Quiz games can be fun, trigger the player's curiosity, can be used in any course and are extremely useful for rehearsing theory [31]. For the creation of the applications' structure we took under consideration the "Conversational Framework", as it was mentioned in the previous section Also, given that a large number of contemporary mobile devices support the android operating system, we chose it in order to develop the present applications. Additionally, through a simple installation process students and teachers can easily access both of the applications on their personal devices.

In the following, we present the design and the development steps of these two educational applications. The structure and functions of these applications cover the following specific objectives:

- The applications' content fully complies with the curriculum of the secondary education courses "Informatics" and "I.P.C.S."

- Learning can be achieved by studying the included in the apps theory and through gaming activities.

- Both applications can be installed on personal devices supporting the Bring Your Own Device (BYOD) trend.

- Both applications can be used during a lesson or outside the classroom settings as well.

The innovation of these applications resides on the fact that their structure supports both formal and informal learning by giving the option to be used in and out of the classroom settings and allow students and teachers to use their own mobile devices, everywhere and anytime. Furthermore, up to this point, there are no other similar educational applications in Greek to address secondary 
education's teachers and students.

\section{EDUCATIONAL APPLICATIONS}

\section{A. The "Informatics" course's curriculum}

As it was briefly mentioned previously, the curriculum of the course D.A.P.E. which was taught in the Greek General Lyceums for nineteen years, since the school year 19992000, was revised and expanded for the course of "informatics" for the school year 2019-2020, including all the previously taught material and adding more chapters relevant to programming principles. This is still a basic course that prepares students for higher education, not only in IT departments but also in many other areas requiring a basic knowledge of algorithmic design [32]. Also, it is a course that was taught for the first time for seven didactic hours per week, both in classrooms and laboratories, and it is examined in the national Pan-Hellenic examinations for entering tertiary education. The course aims on teaching problem solving techniques and on enhance the students' structured thinking. The course's topics include the creation of algorithms and programs, data structures and tables, problem analysis, and debugging.

\section{B. The Aepp_App Application}

The Aepp_App application works with the Android operating system and comes initially in the Greek language. So far, it includes multiple choice questions in the form of quizzes, separated in various categories. The content of the application's quizzes consists of original questions that were written from scratch and follow the "Informatics" course's content. The application was developed in the Android Studio software with the use of the Java programming language and can be installed and work on any smartphone or tablet android device.

During the design process, the database schema, which hosts the data of the users, was implemented and the database was built and locally installed on the device using the application. The implementation of appropriate SQL code enabled communication between the application and the database in order to exchange and update the data. The database stores data such as:

- usernames, passwords and secret answers for password recovery cases,

- the level that each user has reached,

- the prizes that each user has unlocked,

- the opinions of the users about the application, and

- questions created by teachers.

Some of the functions that the Aepp_App application provides include the following:

- Creation of user accounts for teachers and students.

- Creation by teachers of multiple choice questions quizzes by adding their own questions.

- Students can connect to the application and play with the existing multiple choice questions quizzes or the new quizzes that were created by the teachers (Fig. 3).

- Final reports for all answered questions and for errors in answers separately.

- The "Informatics" lesson's theory in the form of questions and answers, separated in units following the school book's structure.
- Multiple levels of difficulty for all types of quizzes.

- Awards and Badges after the completion of each level (Fig. 3).

- The students can give their opinions and rate the application.
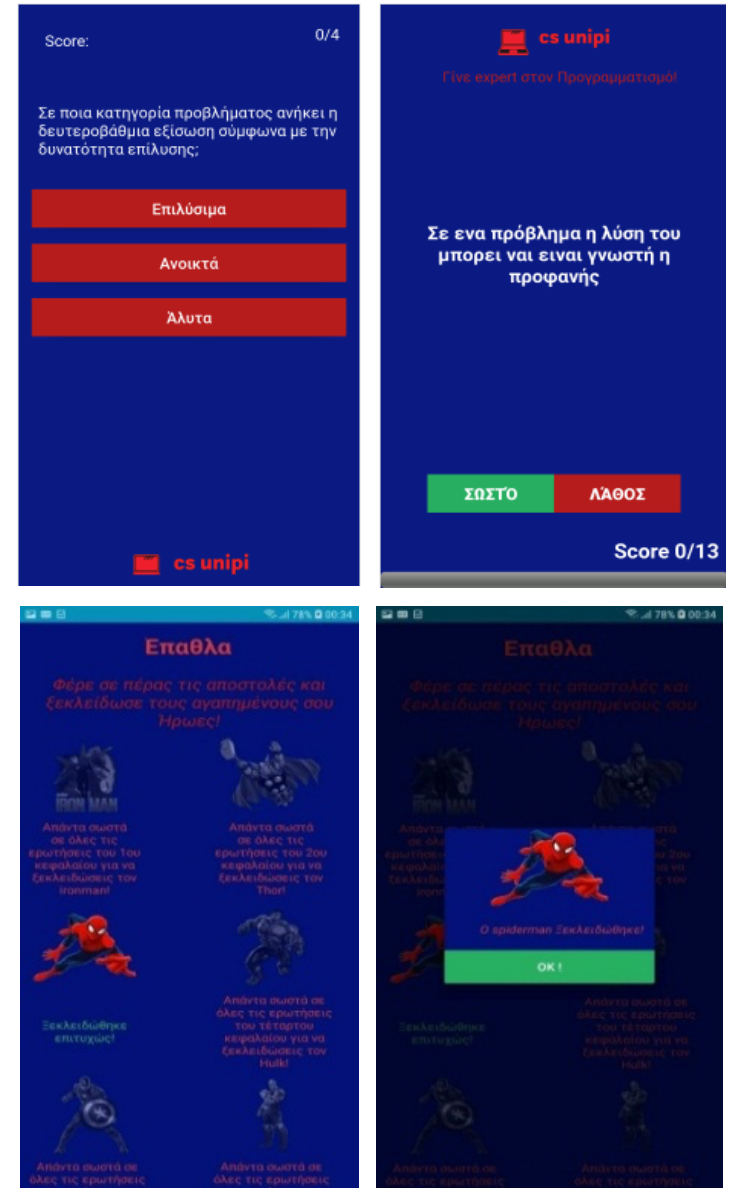

Fig. 3. Aepp_App application's quiz questions and awards and badges screens (in Greek)

The Aepp_App is addressed to both teachers and students for use inside the classroom or outside the school setting in anytime and place. It is possible for teachers to create a variety of tests depending on the part of the curriculum they are teaching using their personal accounts and implement the test completion as an activity during their lesson time or as homework assignment for repetition and reflection. The students can use the application in order to study the theory, take the pre-existing tests or the teacher-generated tests and improve their knowledge.

\section{The "Introduction to the Principles of Computer} Science (I.P.C.S.)" course's curriculum

The purpose of the "I.P.C.S." course is to familiarize students with the fundamental areas and concepts of computer science and informatics and to help them develop analytical and complex thinking [33]. The approach that the course follows is related to both theoretical and applied computer science. In its first part, it covers computer theory issues, like for example from problem to algorithm and from algorithms to programming and its applications, and in its second part provides an overview of key areas of applied computer science (Number of Ministerial Decision: 163615/د2/2-10-2017 - Greek Ministry of Education). It 
has been taught in the 2nd grade of the General and Vocational Lyceums for one didactic hour per week, for the last six years.

\section{The CS_App Application}

The CS_App application can be installed and work on any android mobile device. It was developed again in the Android Studio software with the use of the Java programming language. Technically, it follows a similar design and structure to the Aepp_App application that was described in the previous sub-sections, including an SQLite database that stores all the information about the application's content and also multiple choice questions in the form of quizzes, separated in different categories. The total number of questions so far is 200 . Some functions that the CS_App application provides are the following:

- The "I.P.C.S." course's theory is separated in units (Fig. 4).

- For each unit of theory a multiple choice questions quiz with an adjustable level of difficulty and time constraints is available (Fig. 4).

- After each question, the correct answer is presented in real time.

- Summary of scores, high scores and number of questions.

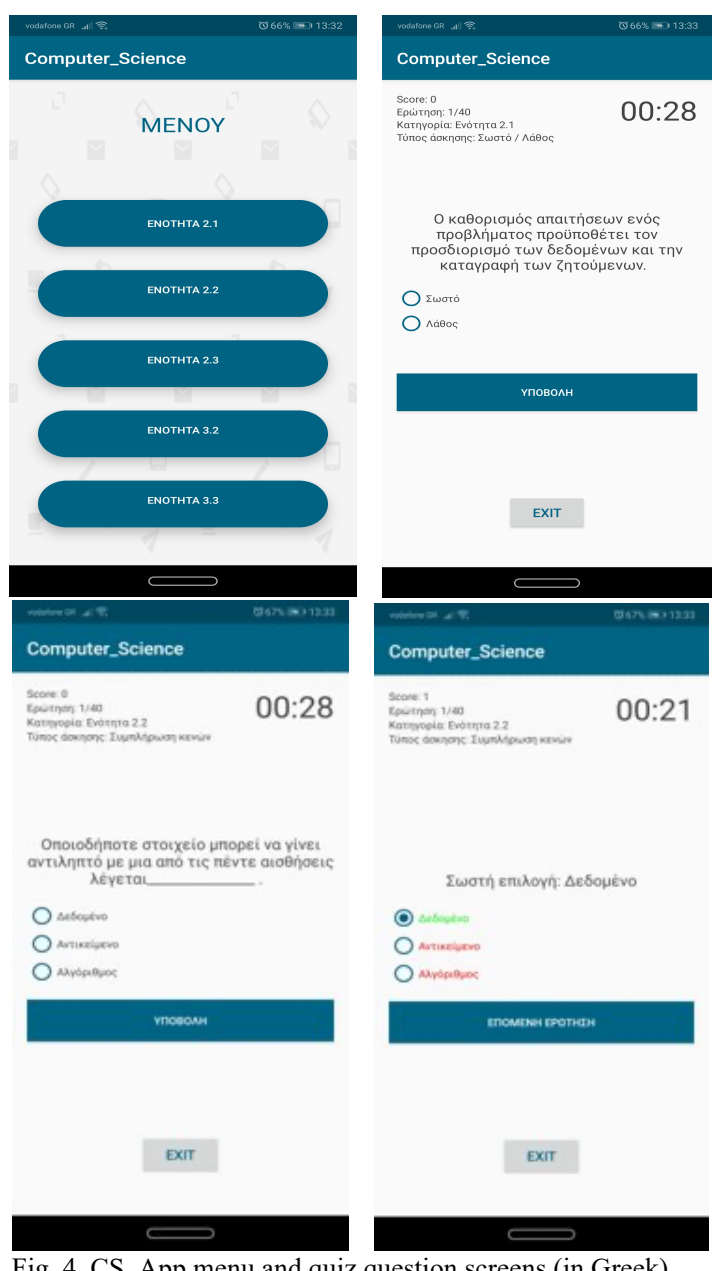

Fig. 4. CS App menu and quiz question screens (in Greek)

CS_App is addressed to students for use supportively with the school lesson in their own devices and in their own time. The students can choose between the different lesson's units, adjust the level of difficulty and take the pre-existing tests in order to improve their knowledge. It is possible for teachers as well to use this application if they wish to implement a different way of teaching and learning in their classroom. Thus, the application can be used for example at the end of a lesson's unit for recapitulation purposes.

\section{Presentation to Teachers}

In July 2020, we performed a 9-hour distance learning lecture, using e-learning tools and techniques, for the course Digital Games in Education, of the postgraduate program studies of "Advanced technologies of Informatics and Services - Technologies of Informatics and Communications in Education" that is organized by the University of West Macedonia and the University of Piraeus, Greece, with the participation of 20 teachers. From those, twelve were women and eight were men and the majority had work experience in education.

In the context of this course, among other topics, the Aepp_app and CS_app applications were presented to the teachers, both by presentation slides and live through camera. In the discussion session that followed in the last didactic hour, we received comments by the teachers who gave us their opinion about the mobile applications. The discussion as a qualitative research method is useful and necessary for understanding the meaning and context of the material studied [34], and in this case helps in gathering the opinions and comments of professionals that are very valuable and can considerably help in technical and content improvements before the implementation of the applications in the teaching process.

During the discussion, the instructor first summarized what was mentioned previously and then posed three questions:

- What is your opinion about the mobile applications presented to you?

- Do you think that the presented mobile applications are appropriate for students and will raise their level of excitement and interest?

- Do you think that learning through using games helps in better understanding of various concepts of Informatics?

The first question aimed in gathering the teachers' general views and opinions about the two applications. The second question focused on the applications' suitability for students and the third question on the applications' potentiality to enhance learning. Some of the answers received are presented in Table I.

TABLE I: SAMPLE OF RECEIVED ANSWERS FROM THE DISCUSSION WITH TEACHERS

\begin{tabular}{ll}
\hline \hline Questions & Answers \\
\hline \multirow{3}{*}{ First Question } & The applications seem to be interesting. \\
& I think that it is a good way of enhancing \\
& learning. \\
& I think that the concept of the applications is \\
Second Question & appropriate for the students. \\
& I think it is fun to learn using a mobile \\
& application game. \\
Third Question & Yes, definetely. \\
& I think playing and learning is more interesting \\
& for our students. \\
\hline \hline
\end{tabular}

As a general result one can say that the teachers think that 
learning through using games is more interesting and they also like the idea of using game applications for mobile devices to enhance their students' interest. Additionally, the teachers gave some suggestions which included comments for the applications' distribution and sharing with the education community.

\section{CONCLUSIONS}

The design and development of applications for mobile devices that serve educational purposes is of great interest, as there are many parameters that need to be considered especially when addressed to secondary school students and teachers.

The present editions of the presented educational applications support gaming activities that aim in making the learning process more flexible, easy and successful. Because they are linked with theoretical frameworks they can be introduced as pedagogical tools and be used supportively to the educational process. A great advantage is the fact that both applications can provide a strong motivation to students through offering gaming activities and through using gaming elements. This, in combination with the lesson's teaching, can give to students the incentive to achieve their desired goals. Taking into account the constructive feedback that we received through our discussion with teachers, we are very positive to the idea that both applications can be useful as educational tools for teachers and students supporting the process of understanding and learning.

\section{FUTURE WORK}

At the time being, we are working on the technical part of the applications, translating them initially in the English language. We will expand both applications' content adding more learning material and extra graphics and multimedia that can make the applications more attractive. Furthermore, we consider adding multiplayer features to give extra motivation for participation to the users. Finally, another addition can be the content expansion of the applications in order to be suitable to be used in other courses as well.

In the immediate future we also to have the applications tested and evaluated by higher education teachers and students in Greece, asking for their opinion and proceeding to improvements wherever needed. Also, we intend to implement the applications in the courses "Informatics" and "I.P.C.S.", during the lessons process, so we currently design and structure educational scenarios which include activities that combine the use of mobile devices with traditional teaching in order for the teachers to use the applications in their lessons.

Although we have a lot of work ahead of us, we strongly believe that it is important to expand the use of mobile devices in secondary education through the development of adequate educational applications because this can be a beneficial way to support teaching and learning.

\section{REFERENCES}

[1] C. C. Chou, L. Block, and R. Jesness, "A Case study of Mobile Learning Pilot Project in K-12 schools," Journal of Educational Technology Development and Exchange (JETDE), vol. 5, iss. 2, Article 3, 2012.
[2] S. Papadakis, and M. Kalogiannakis, "Mobile educational applications for children: what educators and parents need to know," Int. J. Mobile Learning and Organisation, Vol. 11, No. 3, pp. 256277,2017

[3] A. All, J.V. Looy, and E.P. Nunez Castellar, "An evaluation of the added value of co-design in the development of an educational game for road safety," International Journal of Game Based Learning, Vol. 3, Issue 1, pp. 1-17, 2013.

[4] J. Yang, H. Yu, and R. Huang, "The Learning Preferences of Digital Learners in K-12 Schools in China," EURASIA Journal of Mathematics, Science and Technology Education, vol. 12, no.4, pp. 1047-1064, 2016.

[5] J. Byun, and E. Joung, "Digital game-based learning for K-12 mathematics education: A meta-analysis," School Science and Mathematics, vol.118, no.3-4, pp. 113-126, 2018.

[6] M.M.H. Khan, and J.C.L. Chiang, "Using mobile devices amp and social media in supporting engineering education," 2014 IEEE Global Engineering Education Conference (EDUCON), Istanbul, Turkey, 3-5 April 2014, pp. 1077-1081.

[7] S. Judge, "Using mobile media devices and Apps to promote young children's learning," Proceedings of Braga 2014 Embracing Inclusive Approaches for Children and Youth with Special Education Needs Conference, Braga, Portugal, 14-17 July 2014, pp. 142-145.

[8] T. Ott, A. Grigic Magnusson, A. Weilenmann, and Y. Hård af Segerstad, "It must not disturb, it's as simple as that: Students' voices on mobile phones in the infrastructure for learning in Swedish upper secondary school," Education and Information Technologies, Vol. 23, no. 1, pp. 517-536, 2018.

[9] I. Wai, S. Ng, D. Chiu, K. Ho, and P. Lo, "Exploring undergraduate students usage pattern of mobile apps for education," Journal of Librarianship and Information Science, vol. 50, Is. 1, pp. 34-47, 2016.

[10] B. Klímová, "Mobile phones and/or smartphones and their apps for teaching English as a foreign language," Education and Information Technologies, vol. 23, Is. 3, pp. 1091-1099, 2018.

[11] A. Politi, and D. Metafas, "Mobile-assisted learning: designing Class Project Assistant, a research- based educational app for project based learning," 2017 IEEE Global Engineering Education Conference (EDUCON), Athens, Greece, 25-28 April 2017, pp. 667-675.

[12] C.E. Palazzi, "A Mobile Serious Game for Computer Science Learning," 2015 12th Annual IEEE Consumer Communications and Networking Conference (CCNC), Las Vegas, NV, USA, 9-12 Jan 2015, pp. 351-354.

[13] P. B. de Moura Oliveira, "Teaching Automation and Control with App Inventor Applications," 2015 IEEE Global Engineering Education Conference (EDUCON), Tallinn, Estonia, 18-20 March 2015, pp. 879-884.

[14] T. Leinonen, A. Keune, M. Veermans, and T. Toikkanen, "Mobile apps for reflection in learning: a design research in K-12 education," British Journal of Educational Technology, vol. 47, no. 1, pp. 184-202, 2014.

[15] P. Kirci, and M. Oğuzhan Kahraman, "Game based education with android mobile devices," 2015 6th International Conference on Modeling, Simulation, and Applied Optimization (ICMSAO), Istanbul, Turkey, 27-29 May 2015, pp. 1-4.

[16] Google Play Applications (2018). AEPP - The Hero Quest, $\begin{array}{llll}\text { Retrieved: } & \text { December } & 9 & 2019,\end{array}$ https://play.google.com/store/apps/details?id=gr.programatismos_aep $\mathrm{p} \& \mathrm{hl}=\mathrm{el}$

[17] Test4U - The official Test4U blog (2015). AEPP Test4U, Retrieved: December 9 2019, from: http://blog.test4u.eu/tag/Aepp

[18] A. Joyce-Gibbons, D. Galloway, A. Mollel, S. Mgoma, M. Pima, and E. Deogratias, "Mobile phone use in two secondary schools in Tanzania," Education and Information Technologies, vol. 23, no. 1, pp. 73-92, 2018.

[19] K. Clayton, and A. Murphy, "Smartphone Apps in Education: Students Create Videos to Teach Smartphone Use as Tool for Learning," Journal of Media Literacy Education, vol. 8, Is. 2, pp. 99 109, 2016.

[20] J. Mannheimer Zydney, and Z. Warner, "Mobile apps for science learning: Review of research," Computers \& Education, vol. 94, pp. 1-17, 2016.

[21] B. Özmen, and A. Altun, "Undergraduate Students' Experiences in Programming: Difficulties and Obstacles," Turkish Online Journal of Qualitative Inquiry, vol. 5, no 3, pp. 9 - 27, 2014.

[22] B. Klimova, and P. Poulova, "Mobile learning and its potential for engineering education," 2015 IEEE Global Engineering Education Conference (EDUCON), Tallinn, Estonia, 18-20 March 2015, pp. 4751. 
[23] R. Gangaiamaran, and M. Pasupathi, "Review on Use of Mobile Apps for Language Learning," International Journal of Applied Engineering Research, vol. 12, n. 21, pp. 11242-11251, 2017.

[24] V. Persson, and J. Nouri, "A Systematic Review of Second Language Learning with Mobile Technologies," International Journal of Emerging Technologies in Learning (iJET), vol. 13, no. 2, pp. 188210, 2018.

[25] C. de Witt, and C. Gloerfeld, Mobile Learning and Higher Education, In: D. Kergel, B. Heidkamp, P. Telléus, T. Rachwal, S. Nowakowski (eds) The Digital Turn in Higher Education. Springer VS, Wiesbaden, 2018.

[26] H. Hamidi, and A. Chavoshi, "Analysis of the essential factors for the adoption of mobile learning in higher education: A case study of students of the University of Technology," Telematics and Informatics, vol. 35, is. 4, pp. 1053-1070, 2018.

[27] L. F. Alrasheedi, and M. Capretz, "Learner Perceptions of Successful Mobile Learning Platform: a Systematic Empirical," Proceedings of the World Congress on Engineering and Computer Science WCECS 2014, vol. 1, pp. 1-5.

[28] D. Laurillard, Pedagogical forms for mobile learning: framing research questions, In Mobile learning: towards a research agenda, Norbert Pachler, Ed. London: London Knowledge Lab Institute of Education, 2007, ch. 6, pp. 175.

[29] T. Cherner, J. Dix, and C. Lee, "Cleaning up that mess: A framework for classifying educational apps," Contemporary issues in technology and teacher education, vol 14, is. 2, pp. 158-193, 2014.

[30] M. Forehand, (2005). Bloom's taxonomy: Original and revised. In M Orey (Ed.), Emerging perspectives on learning, teaching, and technology, Retrieved: December 7 2019, from: http://www.ctump.edu.vn/DesktopModules/NEWS/DinhKem/4787_9 -A1a-Revised-Bloom-Taxonomy---Why-and-changes.pdf

[31] A. I. Wang, O. K. Mørch-Storstein, and T. Øfsdahl, "Lecture quiz-a mobile game concept for lectures," In Proc. of the 11th IASTED International Conference on Software Engineering and Application (SEA'07), Cambridge, Mass, USA, November 2007, pp. 305-310.

[32] H. Giannopoulos, N. Ioannidis, C. Kilias, K. Malamas, I. Manolopoulos, P. Politis, and A. Vakali, Developing Applications in a Programming Environment. New Technologies Publishing Ed., Athens, Greece: Teaching Publications Organization, Schoolbook of general Lyceum - Pedagogical Institute, 1999, In Greek.

[33] S. Doukakis, C. Douligeris, T. Karvounidis, C. Kilias, and A. Perdos, Introduction to the Principles of Computer Science. New Technologies Publishing Ed., Athens, Greece: Teaching Publications Organization, Schoolbook of general and Vocational Lyceum Institute of Computer Technologies and Publications "Diofantos", 2014, In Greek.

[34] B. Kaplan, and J. A. Maxwell, "Qualitative research methods for evaluating computer information systems," In Evaluating the organizational impact of healthcare information systems. Springer, New York, NY, pp. 30-55, 2005.

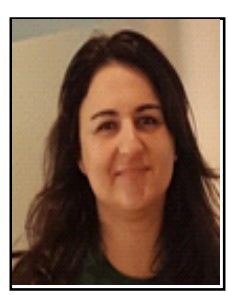

Eleni Seralidou received the BSc in Informatics from the department of Informatics of the Technological Educational Institute of Athens Greece in 2002. She received the MSc in Advanced Information Systems from the department of Informatics of the University of Piraeus - Greece in 2011. Since 2014 she is a $\mathrm{PhD}$ candidate in the department of Informatics of the University of Piraeus. She currently works as an Informatics teacher in secondary education and in addition she works as an adult educator in post-secondary and postgraduate studies. Additionally, from 2014 until today she is a workshop teaching assistant of the courses "Internet Technologies" and "Networks" at the Department of Informatics of the University of Piraeus and a member of the Research Laboratory of Telecommunication Systems, Services and Security (NetLab) of the Department of Informatics of the University of Piraeus, which operates under the supervision of Professor C. Douligeris. She is also the author of several articles in international and local scientific conferences and in scientific journals from 2010 until today.

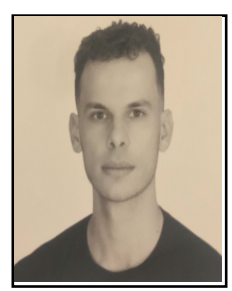

Nikos Vallianatos recently graduated from the Informatics department of the University of Piraeus Greece. His interest lies in solving complex issues and in the art of programming. His main subject of concern, as long as he was studying, was software technologies and intelligent systems and that made him involve either alone or as a member of a team in a lot of projects at the fields of Web development, Mobile development, Artificial Intelligence, Machine learning etc.

His dissertation aimed at developing software that could be used as a useful tool in education.

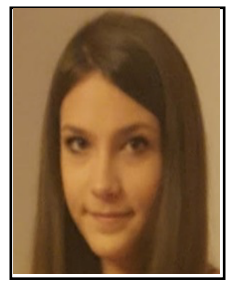

Dimitra Tsolakou recently graduated from the Department of Informatics of the University of Piraeus - Greece. She completed her internship at Titanas Cement - Greece in 2017. Her thesis included the creation of a quiz application for Android smartphones that is intended for use by students and teachers of secondary education. She also attended web design and web programming seminars at Akto College. Finally, she has good English and Spanish language skills.

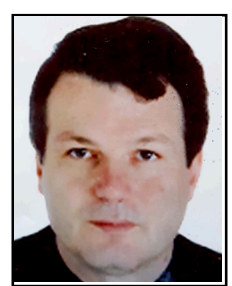

Christos Douligeris, currently a professor at the Department of Informatics, University of Piraeus, Greece held positions with the Department of Electrical and Computer Engineering at the University of Miami. He was an associate member of the Hellenic Authority for Information and Communication Assurance and Privacy and the President and CEO Hellenic Electronic Governance for Social Security SA. Dr. Douligeris has published extensively in the networking scientific literature and he has participated in many research and development projects. His main research interests lie in the areas of communications, networking security, cyber security, educational technologies and the use of technology in all aspects of addressing immigration issues, web science, data analytics, and emergency response operations. 